\title{
KARAKTERISASI MATERIAL POLIMER PVDF DENGAN POLARISASI PERMUKAAN
}

\author{
Aditya Nugraha, Masri Bin Ardin, dan Rivandra Rezani \\ Teknik Perawatan dan Perbaikan Mesin Politeknik Negeri Subang,Subang-IndonesiaJl. Arif \\ Rahman Hakim No.8 (Islamic Centre), Cigadung, Subang, Jawa Barat 41211. \\ Telp. (0260) 417648 \\ E-mail: aditya@polsub.co.id
}

\begin{abstract}
Polivinylidene fluoride (PVDF) is one type of polymer. PVDF is commonly used as a force, heat and strain sensors due to its piezoelectric properties. However, it needs a special process to create the piezoelectric properties of PDVF. One of the special process to create the piezoelectric properties is surface polarization of PVDF. Two electrodes were placed on the surface of PVDF and a high-voltage DC electricity was used for polarization process. In this study, Piezoresponse Force Microscopy (PFM) and Fourier Transformed Infrared (FTIR) was used to determine the results of the surface polarization. The results showed that PVDF with lateral polarization has a more orderly domain direction and a higher $\beta$ phase compared to unpolarized $P V D F$. In addition, the quality decreased with increasing the electrode distance in the lateral polarization.
\end{abstract}

Keywords: PVDF, Surface Polarization, PFM, FTIR.

\section{PENDAHULUAN}

Polyvinylidene fluoride (PVDF) adalah bahan fluoropolymer yang memiliki sifat piezoelektrik dan sifat pyroelektrik yang kuat. Bahan ini banyak digunakan karena memiliki sifat kekakuan yang rendah, respon yang baik, fleksibel, dan ringan. Oleh karena itu, dalam beberapa dekade terakhir, PVDF telah banyak digunakan sebagai sensor dan aktuator [1-4]. Material PVDF diketahui memiliki tiga bentuk struktur molekul yaitu fase $\alpha$, fase $\beta$ dan fase $\gamma$. Di antara tiga struktur tersebut, PVDF dengan struktur fase $\beta$ yang tinggi paling banyak digunakan sebagai sensor dan aktuator karena memiliki efek piezoelektrik terbesar. Semua material PVDF dapat memiliki fase $\beta$, tetapi harus dilakukan suatu teknik fabrikasi tertentu untuk mendapatkannya. Cara agar memiliki fasa $\beta$ yang tinggi PVDF harus melaului proses stretching (penarikan) dengan suhu tertentu dan dilanjutkan dengan polarisasi dengan listrik DC tegangan tinggi $[5,6]$.

Beberapa penelitian menunjukkan bahwa PVDF dapat memiliki fasa $\beta$ tertinggi apabila ditarik dengan suhu $80^{\circ}-90^{\circ} \mathrm{C}[5,6]$. Kestabilan dan kemerataan suhu ketika PVDF ditarik tentunya sangat berpengaruh terhadap kualitas dari PVDF. Ketika PVDF dengan fase $\beta$ diberikan tegangan tinggi, akan ada sebuah sumbu yang berorientasi ke arah sesuai dengan bidang tertentu. Sehingga struktur utama dari PVDF memiliki polaritas yang sesuai dengan orientasi arah medan listrik yang diberikan [7]. Tentunya ada beberapa arah polarisasi yang sering diterapkan pada berbagai material piezoelektrik. Arah polarisasi tersebut dilakukan sesuai kebutuhan. Namun polarisasi PVDF banyak dilakukan dengan meletakkan kedua elektroda di atas dan di bawah lapisan PVDF yang biasa disebut thickness poling $[8,9]$. Sedangkan tidak banyak penelitian yang membahas tentang polarisasi dengan memasang kedua elektroda di atas permukaan PVDF (polarisasi permukaan). Oleh karena itu, penelitian ini mengkaji tentang PVDF dengan polarisasi permukaan. Ruang lingkup penelitian ini adalah untuk mempelajari polarisasi permukaan pada fase dan arah domain kristal PVDF. Piezoresponse Force Microscopy dan Fourier Transformed Infrared (FTIR) digunakan untuk mengetahui arah domain dan besarnya fase $\beta$.

\section{METODE PENELITIAN \\ Stretching (Penarikan)}

Suhu pemanasan dan rasio penarikan adalah faktor penentu yang mempengaruhi perubahan dari fase $\alpha$ ke fase $\beta$. Penelitian ini 
menggunakan lembar tipis PVDF dengan ukuran 100x100 mm dengan ketipisan sebesar $120 \mu \mathrm{m}$. PVDF ditarik di dalam mesin penarik dengan suhu tetap hingga mendapatkan rasio perpanjangan adalah 6 . Dalam penelitian ini, suhu yang digunakan adalah $80^{\circ}$. Ketipisan rata-rata PVDF yang dihasilkan setelah dilakukan penarikan dengan rasio 6 adalah $25 \mu \mathrm{m}$.

\section{Polarisasi}

PVDF memiliki domain feroelektrik yang tidak beraturan. Melalui proses polarisasi dengan tegangan tinggi, domain feroelektrik pada PVDF berubah menjadi lebih beraturan. Kualitas polarisasi ini tentunya dipengaruhi oleh tegangan dan jarak elektroda ketika melakukan polarisasi. Material PVDF dengan arah domain yang lebih beraturan lebih baik untuk dijadikan sensor dibandingkan dengan yang tidak beraturan [5-9].

Gambar 1 merupakan gambaran bagaimana peletakan elektroda pada PVDF dan arah polarisasi yang diberikan. Proses polarisasi dalam penelitian ini menggunakan dua buah elektroda berupa lembaran tembaga tipis yang direkatkan di atas permukaan PVDF. Masingmasing elektroda dipasangkan kabel agar lebih mudah melakukan proses polarisasi. Agar tidak mudah rusak, PVDF diberikan laminasi plastik.

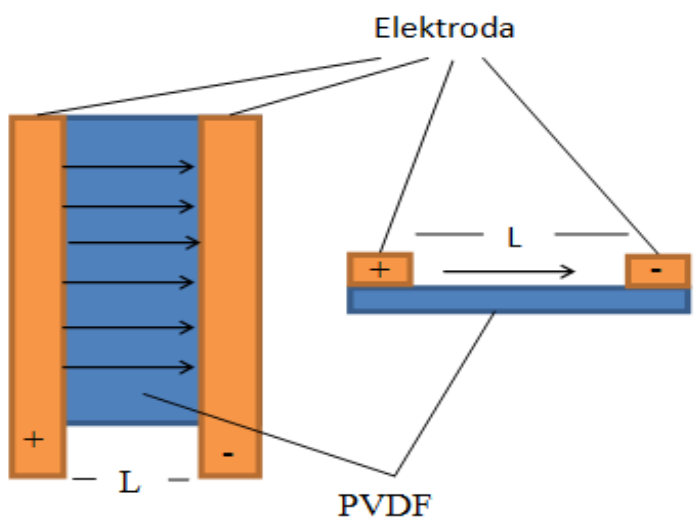

Gambar 1. Polarisasi permukaan pada PVDF

Polarisasi dilakukan dengan nilai $\mathrm{L}$ (jarak elektroda) bervariasi yaitu 2, 4, 6, dan $8 \mathrm{~mm}$. Polarisasi menggunakan tegangan DC sebesar $3.5 \mathrm{KV}$ selama 15 menit dengan suhu ruangan. Gambar PVDF yang telah diberikan elektroda ditunjukkan pada Gambar 2.

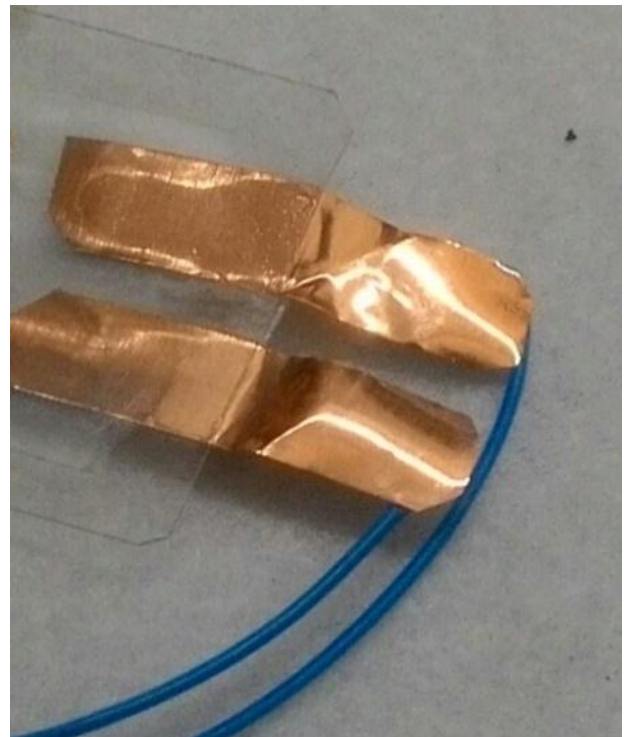

Gambar 2. PVDF dengan kedua elektroda di atasnya

\section{Pengujian dengan Piezoresponse Force Microscopy (PFM)}

Piezoresponse Force Microscopy (PFM) adalah variasi dari Atomic Force Microscopy (AFM). AFM adalah alat yang digunakan untuk pencitraan dan pengukuran permukaan pada suatu material. AFM memanfaatkan cantiliver dengan ukuran yang sangat kecil. Sebuah sinar laser digunakan untuk mengukur kekasaran pada permukaan sampel. Sinar laser dipancarkan ke arah cantiliver yang kemudian dibelokkan ke sensor fotodioda. Sistem umpan balik digunakan untuk menjaga kekonstanan dalam pengukuran [10-12].

Efek invers piezoelektrik diterapkan pada PFM. Ketika AFM sedang memindai sampel, listrik $A C$ tegangan rendah dialrkan melalui ujung cantiliver. Hal ini membuat bahan piezoelektrik menghasilkan deformasi pada permukaan yang sedang diukur. Material dengan domain arah ke bawah akan menyusut ketika diberikan muatan negatif. Sebaliknya, material dengan domain $\mathrm{ke}$ atas akan menyusut jika diberikan muatan positif pada cantiliver [12]. Dalam penelitian ini PFM digunakan untuk melihat hasil polarisasi PVDF dalam bentuk gambar 2D. Keselarasan domain sebelum dan sesudah melakukan polarisasi dapat dilihat menggunakan alat ini. 


\section{Pengujian dengan Fourier Transformed Infrared (FTIR)}

Fourier Transformed Infrared (FTIR) adalah instrumen yang dapat digunakan untuk menganalisis sampel jenis organik maupun anorganik. Dalam penelitian ini, FTIR digunakan untuk mengukur kandungan fase $\beta$ pada PVDF. Rentang gelombang yang digunakan dalam pengukuran ini adalah 650 $1100 \mathrm{~cm}-1$. Tujuan pengukuran ini adalah untuk mengetahui fraksi $\beta$ pada PVDF. Fraksi $\beta$ dihitung dengan Persamaan 1.

$$
F(\beta)=\frac{A_{\beta}}{\left(X_{\beta} / X_{\alpha}\right) A_{\alpha}+A_{\beta}}
$$

Dimana $X \alpha$ dan $X \beta$ adalah koefisien absorbsi pada bilangan gelombang masing, sementara $A \alpha$ dan $A \beta$ adalah nilai absorbansi pada puncak $\alpha$ dan $\beta$ [13].

\section{HASIL DAN PEMBAHASAN}

Gambar 3 menunjukkan gambar respon piezoelektrik yang diukur secara lateral (Lateral PFM). Ketika menggukur dengan PFM, tinta perak $(\mathrm{Ag})$ digunakan sebagai elektroda di bagian bawah PVDF yang ditempelkan dengan besi. Luas permukaan tiap sampel yang diukur adalah $5 \times 5 \mu \mathrm{m} 2$.

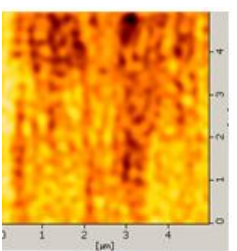

(a)

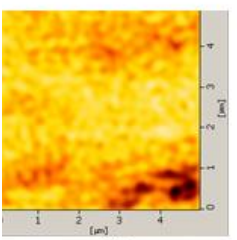

(d)

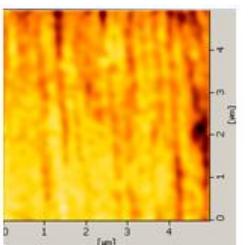

(b)

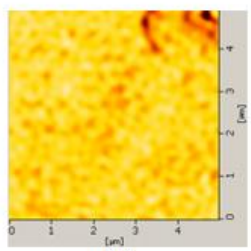

(e)

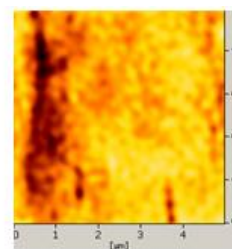

(c)
Gambar 3. Pencitraan PVDF menggunakan PFM pada: (a) PVDF sebelum dipolarisasi, (b) PVDF dengan jarak polarisasi $8 \mathrm{~mm}$, (c) PVDF dengan jarak polarisasi $6 \mathrm{~mm}$, (d) PVDF dengan jarak polarisasi $4 \mathrm{~mm}$, (e) PVDF dengan jarak polarisasi $2 \mathrm{~mm}$
PFM diatur dengan tegangan AC sebesar $15 \mathrm{~V}$ dengan frekuensi $5 \mathrm{KHz}$. Warna gelap dan terang pada gambar PFM menunjukkan polarisasi ke arah positif dan negatif [14-17]. Gambar 3a merupakan hasil tes PFM pada PVDF sebelum dilakukan polarisasi. Pada gambar 3a, tampak sangat jelas warna gelap dan terang saling berbaur, hal ini dikarenakan arah domain yang masih acak (tidak searah). Berbeda halnya dengan gambar 3(b)-3(e) yang merupakan hasil tes PVDF setelah dipolarisasi. Pada hasil tes menggunakan PFM, PVDF yang terpolarisasi terlihat warna terang lebih dominan dan mulai merata. Semakin dekat jarak elektroda ketika polarisasi, maka arah domain yang dihasilkan terlihat semakin searah dan merata.

Tabel 1 menunjukkan nilai koefisien d33 dari PVDF yang diukur menggunakan kurva ZV pada PFM. D33 adalah koefesien perubahan volume material PVDF ketika diberi tegangan. Semakin tinggi nilai d33 pada PVDF maka semakin baik untuk dijadikan sensor [18]. Pada tabel tersebut, terlihat nilai PVDF yang belum dipolarisasi memiliki nilai d33 hanya 21,81 $\mathrm{pm} / \mathrm{V}$. Sedangkan nilai d33 PVDF yang sudah terpolarisasi memiliki nilai d33lebih tinggi. Semaikin jauh jarak elektroda untuk polarisasi, maka semakin kecil nilai d33-nya.

Tabel 1. Nilai d33 menggunakan PFM

\begin{tabular}{|c|c|c|c|c|}
\hline \multicolumn{5}{|c|}{ d33 $(\mathrm{pm} / \mathrm{V})$} \\
\hline $\begin{array}{c}\text { Tidak } \\
\text { Terpolarisasi }\end{array}$ & $\begin{array}{l}\mathrm{L}=8 \\
\mathrm{~mm}\end{array}$ & $\begin{array}{l}\mathrm{L}=6 \\
\mathrm{~mm}\end{array}$ & $\begin{array}{c}\mathrm{L}=4 \\
\mathrm{~mm}\end{array}$ & $\begin{array}{l}\mathrm{L}=2 \\
\mathrm{~mm}\end{array}$ \\
\hline 21,81 & 23,25 & 26,67 & 28,21 & 29,47 \\
\hline
\end{tabular}

Gambar 4 menunjukkan hasil tes PVDF menggunakan FTIR, Hasil tes tersebut terdapat puncak pada grafik yang menunjukkan adanya fraksi $\alpha$ dan $\beta$ pada PVDF. Puncak dari fraksi $\alpha$ dan $\beta$ tersebut berlokasi pada nilai wave number $763 \mathrm{~cm}^{-1}$ dan $840 \mathrm{~cm}^{-1}$. Nilai wave number tersebut merupakan koefesian absorbasi ( $X \alpha$ dan $X \beta$ ). Sedangkan nilai puncak grafik merupakan nilai absorbansi $A \alpha$ dan $A \beta$.

Tabel 2, menunjukkan besarnya nilai fraksi $\beta$ dari PVDF, A $\alpha$ dan $A \beta$. Dari pengukuran FTIR, terlihat bahwa PVDF yang tidak terpolarisasi memiliki fraksi $\beta$ lebih rendah dari pada PVDF yang terpolarisasi, Hal ini dapat dilihat dari jumlah persentasi fraksi $\beta$ PVDF yang tidak terpolarisasi hanya memiliki fraksi $\beta$ 
sebesar $75,4 \%$. Selain itu, jarak elektroda mempengaruhi nilai fraksi $\beta$. Semakin jauh jarak elektroda maka semakin kecil nilai fraksi $\beta$ yang dihasilkan. Hal ini dapat terjadi karena medan polarisasi mempengaruhi tingkat fase $\beta$ [19].

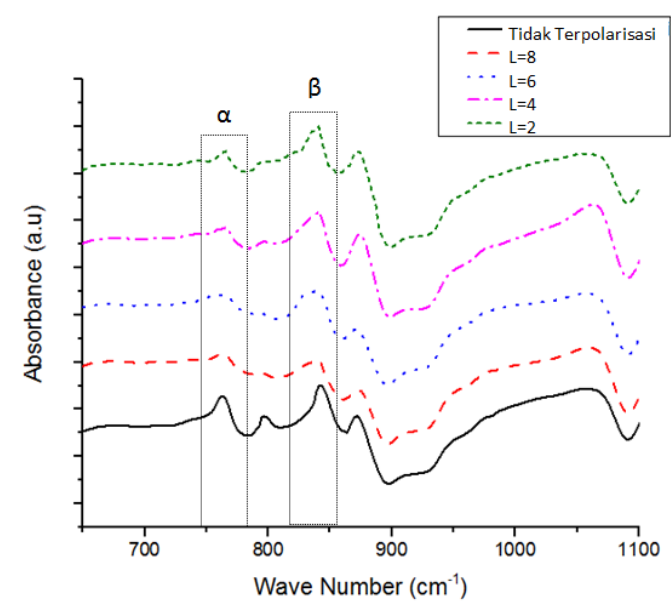

Gambar 4. Hubungan antara Absorbance dan Wave Number dalam Pengetesan PVDF menggunakan FTIR.

Tabel 2. Nilai Absorbansi dan Fraksi $\beta$

\begin{tabular}{cccc}
\hline $\begin{array}{c}\text { Jarak } \\
\text { Polarisasi }\end{array}$ & $\boldsymbol{A}_{\boldsymbol{\alpha}}$ & $\boldsymbol{A}_{\boldsymbol{\beta}}$ & $\mathbf{F}(\boldsymbol{\beta})(\%)$ \\
\hline $\begin{array}{c}\text { Tidak } \\
\text { Terpolarisasi }\end{array}$ & $-0,0036$ & $-0,0149$ & 0,788177 \\
$\mathrm{~L}=8 \mathrm{~mm}$ & 0,00247 & 0,01256 & 0,822029 \\
$\mathrm{~L}=6 \mathrm{~mm}$ & 0,00758 & 0,04672 & 0,848453 \\
$\mathrm{~L}=4 \mathrm{~mm}$ & 0,00631 & 0,0426 & 0,859793 \\
$\mathrm{~L}=2 \mathrm{~mm}$ & 0,00453 & 0,03541 & 0,876547
\end{tabular}

Dalam penelitian ini, PVDF yang telah terpolarisasi digunakan sebagai sensor gaya, Keempat PVDF dengan jarak elektroda berbeda dijatuhkan benda dari ketinggian 50 $\mathrm{mm}$ dengan berat benda sebesar $1 \mathrm{~kg}$, Sinyal listrik yang dihasilkan oleh PVDF diukur menggunakan digital oscilloscope, Hasil PVDF sebagai sensor menunjukkan bahwa respon PVDF dengan elektroda yang lebih dekat dapat menghasilkan sinyal listrik yang lebih tinggi.

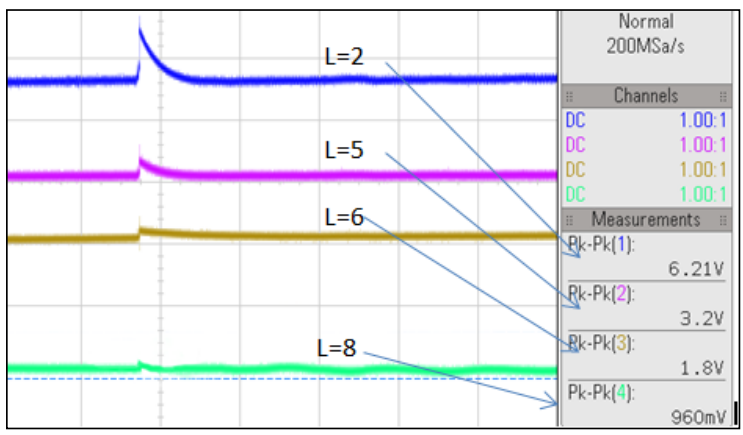

Gambar 5. Sinyal Tegangan PVDF ketika diberi gaya

\section{KESIMPULAN}

Karakterisasi PVDF menggunakan polarisasi lateral dengan jarak yang berbeda berhasil dilakukan. PVDF dengan polarisasi lateral memiliki arah domain yang lebih teratur dan nilai fasa $\beta$ yang lebih tinggi jika dibandingkan dengan PVDF yang belum dipolarisasi. Jarak elektroda pada polarisasi lateral mempengaruhi kualitas dari PVDF sebagai sensor dari segi kesearahan domain, nilai $d 33$, nilai $\beta$ dan tegangan output. Semakin jauh jarak elektroda dalam melakukan polarisasi lateral, maka kualitasnya semakin menurun.

\section{UCAPAN TERIMAKASIH}

Ucapan terimakasih disampaikan kepada Mechanichal Engineering departement, Chung Yuan Christian University, Taiwan dan Prodi TPPM Politeknik Negeri Subang yang telah memberikan kesempatan untuk mengambil data tentang PVDF sehingga penelitian ini berjalan dengan lancar.

\section{DAFTAR PUSTAKA}

[1]. Spanu, A., Pinna, L., Viola, F., Seminara, L., Valle, M., Bonfiglio, A., \& Cosseddu, P., 2016. A high-sensitivity tactile sensor based on piezoelectric polymer PVDF coupled to an ultra-low voltage organic transistor, Organic Electronics, 36, 5760.

[2]. Kwon, K. S., \& Ng, T. N., 2014. Improving electroactive polymer actuator by tuning ionic liquid concentration, Organic Electronics, 15(1), 294-298.

[3]. Saketi, P., Latifi, S. K., Hirvonen, J., Rajala, S., Vehkaoja, A., Salpavaara, T., \& Kallio, P., 2015. PVDF microforce 
sensor for the measurement of Zdirectional strength in paper fiber bonds, Sensors and Actuators $A$ : Physical, 222, 194-203.

[4]. Guzmán, E., Cugnoni, J., \& Gmür, T., 2015. Monitoring of composite structures using a network of integrated PVDF film transducers, Smart Materials and Structures, 24(5), 055017.

[5]. Hartono, A., \& Priyambodo, P., 2016. Pengaruh Polling Medan Listrik Tinggi terhadap Struktur $\beta$ Polyvinylidene Fluoride (PVDF), Al-Fiziya, 9(2), 62-73.

[6]. Gregorio, R., 1994, JR. and M. Cestari. J. Polym. Sci.: B: Polym, Phys, 32, 857.

[7]. Mizuno, M., 2014. Piezoelectric Effects and Materials. In Encyclopedia of Thermal Stresses, Springer Netherlands, pp. 3728-3735.

[8]. Fukada, E., 2000. History and recent progress in piezoelectric polymers. IEEE Transactions on ultrasonics, ferroelectrics, and frequency control, 47(6), 1277-1290.

[9]. Divya, S., \& Hemalatha, J., 2017. Study on the enhancement of ferroelectric $\beta$ phase in $P$ (VDF-HFP) films under heating and poling conditions. European Polymer Journal, 88, 136-147.

[10]. Miao, H., Sun, Y., Zhou, X., Li, Y., \& Li, F., 2014. Piezoelectricity and ferroelectricity of cellular polypropylene electrets films characterized by piezoresponse force microscopy. Journal of Applied Physics, 116(6), 066820.

[11]. Sharma, P., Poddar, S., Korlacki, R., Ducharme, S., \& Gruverman, A., 2014. Investigation of ferroelectric domains in thin films of vinylidene fluoride oligomers, Applied Physics Letters, 105(2), 022906.

[12]. Soergel, E., 2011. Piezoresponse force microscopy (PFM), Journal of Physics D: Applied Physics, 44(46), 464003.
[13]. Cai, X., Lei, T., Sun, D., \& Lin, L., 2017. A critical analysis of the $\alpha, \beta$ and $\gamma$ phases in poly (vinylidene fluoride) using FTIR, RSC Advances, 7(25), 1538215389.

[14]. Sharma, P., Wu, D., Poddar, S., Reece, T. J., Ducharme, S., \& Gruverman, A., 2011. Orientational imaging in polar polymers by piezoresponse force microscopy, Journal of Applied Physics, 110(5), 052010.

[15]. Wang, F., Yang, B., Wei, J., \& Zhang, K., 2014. Microstructure and Nanometer Scale Piezoelectric Properties of c-BN Thin Films With Cu Buffer Layer by Piezoresponse Force Microscopy, IEEE Transactions on Nanotechnology, 13(3), 442-445.

[16]. Schaab, J., Trassin, M., Scholl, A., Doran, A., Yan, Z., Bourret, E., ... \& Meier, D., 2015. Ferroelectric domains in the multiferroic phase of ErMnO3 imaged by low-temperature photoemission electron microscopy, In Journal of Physics: Conference Series (Vol. 592, No. 1, p. 012120). IOP Publishing.

[17]. Baji, A., Mai, Y. W., Li, Q., \& Liu, Y., 2011. Nanoscale investigation of ferroelectric properties in electrospun barium titanate/polyvinylidene fluoride composite fibers using piezoresponse force microscopy, Composites Science and Technology, 71(11), 1435-1440.

[18]. Mohammadi, B., Yousefi, A. A., \& Bellah, S. M., 2007. Effect of tensile strain rate and elongation on crystalline structure and piezoelectric properties of PVDF thin films, Polymer testing, 26(1), 42-50.

[19]. Furukawa, T., Date, M., \& Fukada, E., 1980. Hysteresis phenomena in polyvinylidene fluoride under high electric field, Journal of Applied Physics, 51(2), 1135-1141. 